\title{
Construction of Polygonatum sibiricum Polysaccharide Functionalized Selenium Nanoparticles for the Enhancement of Stability and Antioxidant Activity
}

\author{
Wanwen Chen ${ }^{1,2}$, Hao Cheng ${ }^{1, *(D)}$ and Wenshui Xia ${ }^{1,2}$ \\ 1 State Key Laboratory of Food Science and Technology, School of Food Science and Technology, \\ Jiangnan University, Wuxi 214122, China; wwchen@jiangnan.edu.cn (W.C.); xiaws@jiangnan.edu.cn (W.X.) \\ 2 Collaborative Innovation Center of Food Safety and Quality Control in Jiangsu Province, Jiangnan University, \\ Wuxi 214122, China \\ * Correspondence: haocheng@jiangnan.edu.cn
}

Citation: Chen, W.; Cheng, H.; Xia, W. Construction of Polygonatum sibiricum Polysaccharide Functionalized Selenium Nanoparticles for the Enhancement of Stability and Antioxidant Activity. Antioxidants 2022, 11, 240. https:// doi.org/10.3390/antiox11020240

Academic Editor: Stanley Omaye

Received: 20 December 2021

Accepted: 26 January 2022

Published: 26 January 2022

Publisher's Note: MDPI stays neutral with regard to jurisdictional claims in published maps and institutional affiliations.

Copyright: (C) 2022 by the authors. Licensee MDPI, Basel, Switzerland. This article is an open access article distributed under the terms and conditions of the Creative Commons Attribution (CC BY) license (https:// creativecommons.org/licenses/by/ $4.0 /)$.

\begin{abstract}
Although selenium nanoparticles (SeNPs) have attracted great attention due to their potential antioxidant activity and low toxicity, the application of SeNPs is still restricted by their poor stability. A combination of polysaccharides and SeNPs is an effective strategy to overcome the limitations. In this study, Polygonatum sibiricum polysaccharide (PSP) was used as a stabilizer to fabricate SeNPs under a simple redox system. Dynamic light scattering, transmission electron microscopy, energy dispersive X-ray, ultraviolet-visible spectroscopy, Fourier transform infrared, and X-ray photoelectron spectrometer were applied to characterize the synthesized PSP-SeNPs. The stability and the antioxidant activity of PSP-SeNPs were also investigated. The results revealed that the zero-valent and well-dispersed spherical PSP-SeNPs with an average size of $105 \mathrm{~nm}$ and a negative $\zeta$-potential of $-34.9 \mathrm{mV}$ were successfully synthesized using $0.1 \mathrm{mg} / \mathrm{mL}$ PSP as a stabilizer. The prepared PSP-SeNPs were stable for 30 days at $4{ }^{\circ} \mathrm{C}$. The decoration of the nanoparticle surface with PSP significantly improved the free radical scavenging ability of SeNPs. Compared to the $\mathrm{H}_{2} \mathrm{O}_{2}$-induced oxidative stress model group, the viability of PC-12 cells pretreated with $20 \mu \mathrm{g} / \mathrm{mL}$ PSP-SeNPs increased from $56 \%$ to $98 \%$. Moreover, PSP-SeNPs exhibited a higher protective effect on the $\mathrm{H}_{2} \mathrm{O}_{2}$-induced oxidative damage on PC-12 cells and lower cytotoxicity than sodium selenite and SeNPs. In summary, these results suggest the great potential of PSP-SeNPs as a novel antioxidant agent in the food or nutraceuticals area.
\end{abstract}

Keywords: selenium nanoparticles; Polygonatum sibiricum polysaccharide; stability; antioxidant

\section{Introduction}

Selenium is an essential micronutrient for humans and animals [1]. It is an integral component of more than 30 kinds of selenoproteins and selenium-containing enzymes, such as selenoprotein P (SelP), selenoprotein S (SelS), selenoprotein M (SelM), subfamilies of thioredoxin reductases (TrxR), glutathione peroxidases (GPx), and iodothyronine deiodinases (ID), that play a key role in regulating redox balance and preventing cellular damage from radicals [2,3]. However, at least one billion people in the world are at risk of selenium deficiency at present because the intake of selenium is insufficient to meet the daily requirement [4]. Epidemiological studies established that selenium deficiency is associated with many diseases, including premature aging, a decline in sperm motility, myocardial failure, neurological diseases, endemic osteoarthropathy (Keshan disease), and ischemic heart disease [5]. Although high-dose sodium selenite, methyl selenium, and selenocysteine exhibit excellent bioactivities, they can also result in serious toxicity problems, leading to many diseases [6]. Thus, it is of great importance to seek novel selenium species as food supplements or additives. 
Selenium nanoparticles (SeNPs) have gained much attention owing to their unique physical, chemical, and antioxidant activities [7]. Moreover, SeNPs have higher bioavailability and lower toxicity in comparison to other chemical forms of selenium, making them the promising alternative selenium source in food dietary [8]. However, SeNPs alone with valence state zero are highly unstable in an aqueous solution and easily transform to aggregate, resulting in lower bioactivity and further limiting their practical application [9]. Many efforts have been made to develop a simple, efficient, and green strategy for the dispersion and stabilization of SeNPs using bioactive templates [10]. Natural polysaccharides not only have complex structures, large specific surface areas, and ionizable functional groups but also possess excellent biocompatibility and biodegradability [11]. These features could decrease the surface energy of SeNPs, further preventing aggregation through electrostatic interaction or hydrogen bonds. Thus, polysaccharides applied as carriers to fabricate SeNPs with desired characteristics, such as stability and functionality, using the green chemical method is drawing much attention recently. For example, numerous studies reported that chitosan (CS) could be used as templates to prepare uniform SeNPs and the ligated SeNPs remain stable for over 1 month [12]. However, the superior properties of CS are limited due to its water insolubility and our previous research also found that CS-SeNPs aggregated under alkaline conditions $(\mathrm{pH} \geq 9)$ [13]. Several polysaccharides derived from fungi [14], fruit [15], and medicinal plants [16] have been demonstrated to enhance the antioxidant activity of SeNPs. Recently, medicinal plant polysaccharides have attracted increasing attention due to their significant bioactivities with no side effects [17]. Therefore, it can be expected that the combination of medicinal plant polysaccharides with SeNPs will reduce the inherent limitations and enhance the benefits of selenium and polysaccharides.

Polygonatum sibiricum is a traditional Chinese herbal medicine, belonging to the Liliaceae family, which has been introduced in the 2015 edition of pharmacopeia [18]. China has abundant resources of Polygonatum sibiricum, especially in the south of the Yangtze River [19]. The constituents of P. sibiricum include polysaccharides, saponins, flavonoids, alkaloids, lignin, vitamins, and a variety of trace elements, of which polysaccharides are the major pharmacologically active ingredients [20]. In the last three years, Polygonatum sibiricum polysaccharides (PSP) are demonstrated to exhibit a wide range of pharmacological activity [21], such as osteogenic activity [22], anti-diabetes [23], immunological activity [24], and especially antioxidant activity, which makes them suitable for application in functional foods and therapeutic agents. PSP demonstrated strong antioxidant properties, which could attenuate D-gal-induced heart aging [25] and protect the mice livers against ethanolinduced oxidative damage via inhibiting oxidative stress [26]. However, no study has been reported using PSP as a decorator to functionalize SeNPs.

In this study, considering the antioxidant activity of PSP as well as the drawbacks of SeNPs, a combined strategy was conducted to fabricate SeNPs using PSP as a stabilizer in the redox system of sodium selenite $\left(\mathrm{Na}_{2} \mathrm{SeO}_{3}\right)$ and ascorbic acid $(\mathrm{Vc})$ through a simple chemistry approach. The synthesized PSP functionalized SeNPs (PSP-SeNPs) were characterized by dynamic light scattering (DLS), transmission electron microscopy (TEM), energy dispersive X-ray (EDX), ultraviolet-visible spectroscopy (UV-vis), Fourier transform infrared (FTIR), and X-ray photoelectron spectrometer (XPS). The physicochemical stabilities of synthesized nanoparticles under varying conditions, including ionic strength, $\mathrm{pH}$, and temperature, were analyzed. In addition, the antioxidant activity of PSP and PSP-SeNPs was quantified by ABTS and DDPH free radical scavenging assays. Moreover, the protective effect on the $\mathrm{H}_{2} \mathrm{O}_{2}$-induced cell death was also investigated by MTT assay.

\section{Materials and Methods}

\subsection{Reagents}

Commercial Polygonatum sibiricum polysaccharide (PSP) with a purity of $95 \%$ and a molecular weight of $14 \mathrm{kDa}$ was obtained from Qiannuo Biotechnology Co. Ltd. (Xi'an, China), sodium selenite $\left(\mathrm{Na}_{2} \mathrm{SeO}_{3}\right)$, hydrogen peroxide $\left(\mathrm{H}_{2} \mathrm{O}_{2}\right)$, ascorbic acid $(\mathrm{Vc})$, potassium persulfate $\left(\mathrm{K}_{2} \mathrm{~S}_{2} \mathrm{O}_{8}\right)$, 1, 1-diphenyl-2-picrylhydrazyl (DPPH), 2, 2-azinobis (3-ethylbenzothiazoline-6- 
sulfonic acid) and diammonium salt (ABTS) were purchased from Sinopharm Chemical Reagent Co., Ltd. (Shanghai, China). All chemicals used were of analytical grade, and the water used in all experiments was obtained from the Milli-Q system.

\subsection{Preparation of SeNPs and PSP Stabilized SeNPS}

PSP-SeNPs were prepared according to the procedure described by Ye et al. with minor modification [8]. PSP stock solution $(5 \mathrm{mg} / \mathrm{mL})$ was freshly prepared. Where $1 \mathrm{~mL}$ of sodium selenite solution $(50 \mathrm{mM})$ was mixed with various volumes of PSP solution under stirring for $5 \mathrm{~min}$. Then $1 \mathrm{~mL}$ of ascorbic acid solution $(200 \mathrm{mM})$ was added dropwise into the mixture, and it was reconstituted to a final volume of $10 \mathrm{~mL}$ with Milli- $\mathrm{Q}$ water. The reaction was carried out at room temperature for $30 \mathrm{~min}$. Finally, the solution was dialyzed using regenerated cellulose tubes ( $\mathrm{Mw}$ cutoff $3500 \mathrm{Da}$ ) against ultrapure water for $48 \mathrm{~h}$ at $4{ }^{\circ} \mathrm{C}$. The final concentrations of PSP were $0.01,0.05,0.075,0.1,0.125,0.15$, $0.25 \mathrm{mg} / \mathrm{mL}$. SeNPs were synthesized in the absence of PSP through the same procedure as above. The resultant products were lyophilized to obtain the freeze-dried nanocomposites. The concentration of selenium was determined by the Optima 8300 inductively coupled plasma optical emission spectrometer (ICP-OES, PerkinElmer, Billerica, MA, USA).

\subsection{Characterization}

The mean diameter, size distribution, and $\zeta$-potential of nanocomposites were determined using a Zetasizer Nano ZS analyzer (Malvern Instruments Corporation, Worcestershire, UK). The morphology was observed using transmission electron microscopy (TEM) (JEOL, JEM-2100, Tokyo, Japan). Samples for TEM observation were prepared by placing one drop of SeNPs and PSP-SeNPs aqueous solution on a carbon-coated copper grid and dried at room temperature. The micrographs were acquired at the accelerating voltage of $200 \mathrm{kV}$. The elemental composition and distribution were determined by the energy dispersive $\mathrm{X}$-ray (EDX) analysis performed on a high-resolution transmission electron microscopy (HRTEM) (JEOL, JEM-2100, Tokyo, Japan). The ultraviolet-visible (UV-vis) spectrophotometer (UV1800, Shimadzu Corporation, Tokyo, Japan) was used to measure the UV-vis absorption spectra of SeNPs and PSP-SeNPs solutions in the wavelength range of 190-800 nm with an interval of $1.0 \mathrm{~nm}$. The Fourier transform infrared (FTIR) spectra were recorded on a Nicolet iS 10 instrument (Thermo Fisher Scientific, Waltham, MA, USA). Each sample was grounded with $\mathrm{KBr}$, pressed into uniform pellets, and scanned in the wavenumber range of $4000-400 \mathrm{~cm}^{-1}$ with a resolution of $4.0 \mathrm{~cm}^{-1}$ using pure $\mathrm{KBr}$ as the background. The X-ray photoelectron spectrometer (XPS) was used to analyze the valence states of the elements. The XPS patterns were operated on a Thermo Scientific ESCALab 250Xi+ (Thermo Fisher Scientific, Waltham, MA, USA) using $150 \mathrm{~W}$ monochromated $\mathrm{Al} \mathrm{K \alpha}$ radiation.

\subsection{Stability of PSP-SeNPS}

The stability of PSP-SeNPs under various conditions was investigated according to the methods described previously [27]. To determine the effect of ionic concentration on stability, $10 \mathrm{~mL}$ of PSP-SeNPs were mixed with different concentrations of $\mathrm{NaCl}$ solution $(10,50$, and $100 \mathrm{mM})$. The effect of $\mathrm{pH}$ on the stability of NPs was analyzed by adjusting the $\mathrm{pH}$ of PSP-SeNPs to 2, 3, 4, 5, 6, 7, 8, 9, and 10 using $0.1 \mathrm{M} \mathrm{HCl}$ or $\mathrm{NaOH}$. Where $10 \mathrm{~mL}$ of PSP-SeNPs were incubated in a water bath at different temperatures $\left(25,50,70\right.$, and $\left.90^{\circ} \mathrm{C}\right)$ to investigate the effect of temperature on the stability of PSP-SeNPs. After being stabilized for $1 \mathrm{~h}$, their mean diameter and $\zeta$-potential were determined using a Zetasizer Nano ZS analyzer. In addition, PSP-SeNPs solutions were stored at $4{ }^{\circ} \mathrm{C}$ for 30 days to investigate the short-term storage stability by determining the mean diameter and $\zeta$-potential.

\subsection{Antioxidant Assays}

\subsubsection{DPPH Radical Scavenging Ability}

The DPPH radical scavenging activity was determined referring to the methods reported previously with minor modifications [14]. Various concentrations of PSP, SeNPs, 
PSP-SeNPs, and Vc at $0.01,0.05,0.1,0.25,0.5,0.75,1.0 \mathrm{mg} / \mathrm{mL}$ were prepared. Further, $2 \mathrm{~mL}$ of the sample solutions were mixed with an equal volume of freshly prepared DPPH solution (50 mg/L) in ethanol. The mixture was shaken vigorously and incubated in darkness at $33{ }^{\circ} \mathrm{C}$ for $30 \mathrm{~min}$. The absorbance was measured at $517 \mathrm{~nm}$ using a UVvis spectrophotometer. Vc was used as a positive control. The scavenging activity was calculated as follows:

$$
\text { DPPH radical scavenging ability }(\%)=\left(1-\frac{\mathrm{A}_{\mathrm{a}}-\mathrm{A}_{\mathrm{b}}}{\mathrm{A}_{\mathrm{c}}}\right) \times 100
$$

where $A_{a}$ is the absorbance of the sample mixed with DPPH solution, $A_{b}$ is the absorbance of the sample in the absence of the DPPH solution, $A_{c}$ is the absorbance of the DPPH solution without the sample as a blank control.

\subsubsection{ABTS Radical Cation Decolonization Assay}

The assay of ABTS radical cation scavenging ability was performed as described previously with some modification [28]. ABTS and potassium persulfate $\left(\mathrm{K}_{2} \mathrm{~S}_{2} \mathrm{O}_{8}\right)$ were dissolved in distilled water. A stock solution of $\mathrm{ABTS}^{\bullet+}$ was prepared by mixing $7.4 \mathrm{mM}$ ABTS solution with $2.6 \mathrm{mM} \mathrm{K} \mathrm{S}_{2} \mathrm{O}_{8}$ solution. The mixture was incubated for $12 \mathrm{~h}$ in the dark to reach equilibrium. The $\mathrm{ABTS}^{\bullet+}$ stock solution was diluted with sodium phosphate buffer ( $\mathrm{pH} 7.4$ ) to obtain an optical density of $0.70 \pm 0.02$ at $734 \mathrm{~nm}$. Then $1 \mathrm{~mL}$ of different concentrations of PSP, SeNPs, PSP-SeNPs, and Vc $(0.01,0.05,0.1,0.25,0.5,0.75,1.0 \mathrm{mg} / \mathrm{mL})$ was added to $4 \mathrm{~mL}$ of diluted $\mathrm{ABTS}^{\bullet+}$ solution. The mixture was vigorously blended and incubated at room temperature for $6 \mathrm{~min}$ in darkness. The absorbance was measured at $734 \mathrm{~nm}$ using a UV-vis spectrophotometer. The ability to scavenge ABTS $^{\bullet+}$ was calculated by Equation (2).

$$
\mathrm{ABTS}^{\bullet}+\text { radical scavenging ability }(\%)=\left(1-\frac{\mathrm{A}_{\mathrm{d}}-\mathrm{A}_{\mathrm{e}}}{\mathrm{A}_{\mathrm{f}}}\right) \times 100
$$

where $A_{d}$ is the absorbance of the sample mixed with the ABTS ${ }^{\bullet+}$ solution, $A_{e}$ is the absorbance of the sample in the absence of the $\mathrm{ABTS}^{\bullet+}$ solution, $\mathrm{A}_{\mathrm{f}}$ is the absorbance of the $\mathrm{ABTS}^{\bullet+}$ solution without the sample.

\subsection{Cells Culture and MTT Assays}

PC-12 cells were cultured in Dulbecco's modified Eagle's medium (DMEM) supplemented with $10 \%$ fetal bovine serum (FBS) and $1 \%$ antibiotic mixture $(100 \mathrm{U} / \mathrm{mL}$ penicillin and $100 \mu \mathrm{g} / \mathrm{mL}$ streptomycin). The cytotoxic effects of different selenium concentrations of PSP-SeNPs, SeNPs, and $\mathrm{Na}_{2} \mathrm{SeO}_{3}$ on cells were tested using MTT assays [15]. Cells were seeded in a 96-well plate at a density of $1 \times 10^{4}$ cells / well and incubated at $37^{\circ} \mathrm{C}$ in a $\mathrm{CO}_{2}$ incubator (5\% CO $\mathrm{CO}_{2}$ and $95 \%$ relative humidity) for $24 \mathrm{~h}$. Then the medium was removed and cells were treated with different concentrations of samples prepared in DMEM with $10 \%$ FBS for an additional $24 \mathrm{~h}$. After incubation, $20 \mu \mathrm{L}$ of MTT ( $5 \mathrm{mg} / \mathrm{mL})$ was added to each well and incubated at $37^{\circ} \mathrm{C}$ for $3 \mathrm{~h}$. Then the supernatant was removed and $150 \mu \mathrm{L}$ of DMSO was added. The absorbance was measured by a microplate reader at $570 \mathrm{~nm}$. The cell viability was calculated by Equation (3).

$$
\text { Cell viability }(\%)=\mathrm{OD}_{\text {sample }} / \mathrm{OD}_{\text {control }} \times 100
$$

where $\mathrm{OD}_{\text {sample }}$ is the absorbance of the treated cells and $\mathrm{OD}_{\text {control }}$ is the absorbance of the control cells.

To determine the protective effect of PSP-SeNPs, SeNPs, and $\mathrm{Na}_{2} \mathrm{SeO}_{3}$ on $\mathrm{H}_{2} \mathrm{O}_{2}$ induced cell cytotoxicity, cells were pre-incubated with different selenium concentrations of samples prepared in DMEM with 10\% FBS for $24 \mathrm{~h}$. After incubation, the medium was removed and cells were washed with PBS. Then cells were treated with a medium 
containing $500 \mu \mathrm{M} \mathrm{H}_{2} \mathrm{O}_{2}$ for $12 \mathrm{~h}$. The medium was removed and the cell viability was determined by MTT assay as described above.

\subsection{Statistical Analysis}

All the experiments were performed at least in triplicate. The results were expressed as mean \pm standard deviation (SD). Statistical analysis was carried out using paired t-tests for comparing means of two samples by the SPSS 20.0 statistical software (IBM, Armonk, NY, USA). Statistical differences between samples were performed with a level of significance of $p<0.05$.

\section{Results}

\subsection{The Synthesis of SeNPs and PSP-SeNPs}

In the present study, SeNPs and PSP-SeNPs were prepared using a simple redox system of ascorbic acid and sodium selenite in the absence and presence of PSP as the stabilizer and capping agent. The visual color of the reaction solution is an indicator to preliminary infer the formation of selenium nanoparticles [29]. As shown in Figure 1, the red color of the solution indicated the $\mathrm{SeO}_{3}{ }^{2-}$ was successfully reduced to either monoclinic or amorphous SeNPs [16]. In addition, the SeNPs in the presence of PSP showed a uniform red color and were stable in the aqueous solution. However, SeNPs without the decoration of PSP aggregated into precipitation after 1 day of storage, whereas no significant changes were observed in the solution of PSP-SeNPs. This might be attributed to the high surface energy, leading to the aggregation of SeNPs [9]. Hence, PSP plays a key role in the formation and stabilization of SeNPs.

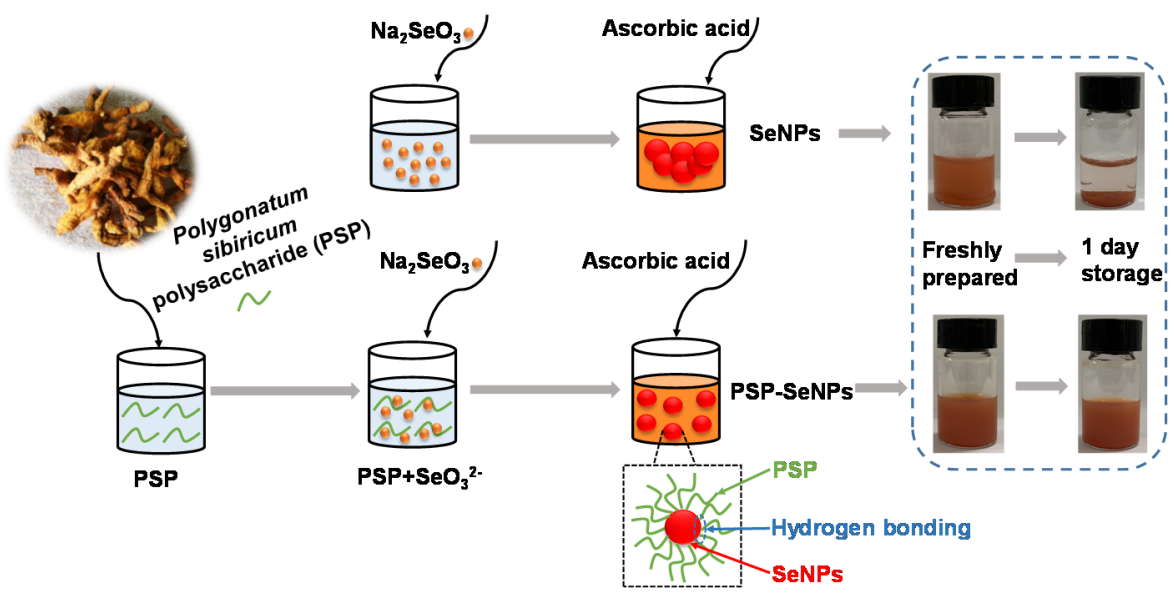

Figure 1. Synthetic scheme for the preparation of selenium nanoparticles (SeNPs) and Polygonatum sibiricum polysaccharide stabilized selenium nanoparticles (PSP-SeNPs) and images of the dispersions before and after storage for 1 day.

\subsection{The Size and $\zeta$-Potential Analysis of SeNPs and PSP-SeNPs}

The concentration of the polysaccharides is an important factor that influences the size of SeNPs, further affecting their functionality in food or medical application [30]. Thus, the effect of PSP concentrations on the hydrated particle size and the corresponding polydispersity index (PDI), as well as the $\zeta$-potential of nanoparticles in the aqueous solution was investigated first. The particle size of barely SeNPs was up to $157 \mathrm{~nm}$ (Figure 2A). The addition of PSP at different concentrations could decrease the average size of SeNPs. The average diameter of PSP-SeNPs significantly decreased from 151 to $132 \mathrm{~nm}$ as the concentration of PSP increased from 0.01 to $0.075 \mathrm{mg} / \mathrm{mL}$. PSP-SeNPs showed the smallest average size of $114 \mathrm{~nm}$ at the PSP concentration of $0.1 \mathrm{mg} / \mathrm{mL}$, whereas further increases in PSP concentration from 0.125 to $0.25 \mathrm{mg} / \mathrm{mL}$ resulted in an increase in the size from 123 to $152 \mathrm{~nm}$. It might be due to PSP at a low concentration was not enough to control the formation of SeNPs and prevent them from aggregation [31]. On the other hand, too high 
PSP concentration represented more PSP chains coated on the surface of SeNPs, resulting in a larger hydration particle size [32]. As shown in Figure 2B, SeNPs in the absence of PSP exhibited a negative $\zeta$-potential at $-20.3 \mathrm{mV}$. The $\zeta$-potential values of PSP-SeNPs were determined to be approximately $-24.7,-26.6,-29.6,-30.4,-32.8,-34.9 \mathrm{mV}$ at the PSP concentration of $0.01,0.05,0.075,0.1,0.125,0.25 \mathrm{mg} / \mathrm{mL}$. The absolute $\zeta$-potential values of PSP-SeNPs increased with the PSP concentration increasing, further demonstrating that negatively charged PSP was exposed on the surface of SeNPs. Moreover, the higher magnitude of $\zeta$-potential represents greater stability of nanoparticles [13], suggesting that the SeNPs decorated with PSP possess higher stability than barely SeNPs. PSP-SeNPs prepared by $0.1 \mathrm{mg} / \mathrm{mL}$ PSP were used in the following experiments.
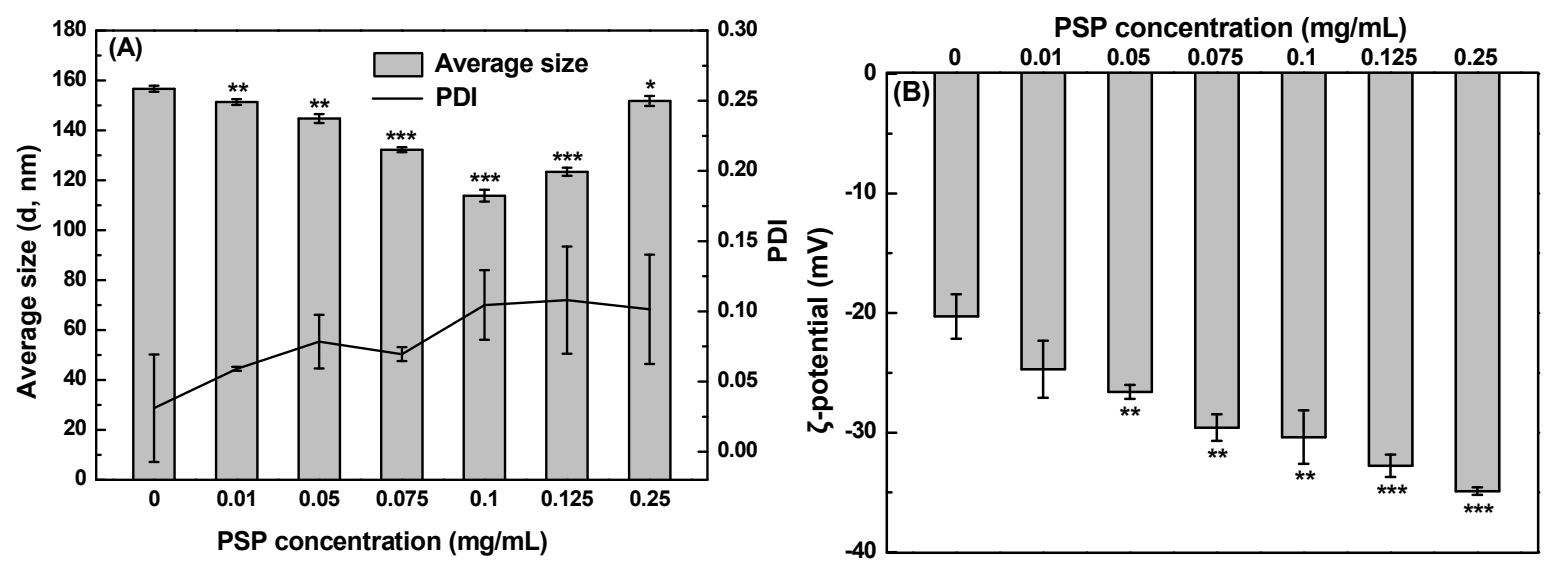

Figure 2. Size distribution (A) and $\zeta$-potential (B) of SeNPs and PSP-SeNPs prepared with different concentrations of PSP $(0.01-0.25 \mathrm{mg} / \mathrm{mL})$. Values marked with ${ }^{*}: p<0.05,{ }^{* *}: p<0.01$, and $* * *: p<0.001$ indicated significant differences when compared to SeNPs.

\subsection{Morphological and Structural Characterizations of SeNPs and PSP-SeNPs}

The morphology and size of SeNPs and PSP-SeNPs were further characterized by TEM. Figure 3A,B exhibited the TEM images of SeNPs in the absence of PSP. The results showed that adjacent SeNPs agglomerated together and presented a dendritic structure. The large-sized cluster and aggregates can also be easily visualized. However, the SeNPs in the presence of $0.1 \mathrm{mg} / \mathrm{mL}$ PSP (Figure 3C,D) exhibited a homogeneous and monodisperse spherical structure with an average size of about $105 \mathrm{~nm}$, confirming the important role of PSP in regulating and stabilizing SeNPs. It should be pointed out that the hydrodynamic radius of the nanoparticles provided in the DLS analysis was larger than the size observed in the TEM image, which was sensitive to the electron-rich nanoparticles. The HRTEM image (Figure 3E) of an individual PSP-SeNPs showed a distinct lattice fringe with an interplanar spacing of $0.43 \mathrm{~nm}$, revealing the excellent crystallinity of PSP-SeNPs. The elemental composition and distribution of the PSP-SeNPs were further determined by EDX. As shown in Figure 3F, the strong C, O, and Se element peaks were observed in EDX spectra. The PSP-SeNPs had a $63.10 \%$ weight percentage of $C$ atom, together with $10.95 \%$ $\mathrm{O}$ atom and $25.94 \%$ Se atom. Furthermore, no other peaks for other elements were detected, indicating that PSP was successfully coated on the surface of SeNPs and confirming the purity of PSP-SeNPs [33]. 

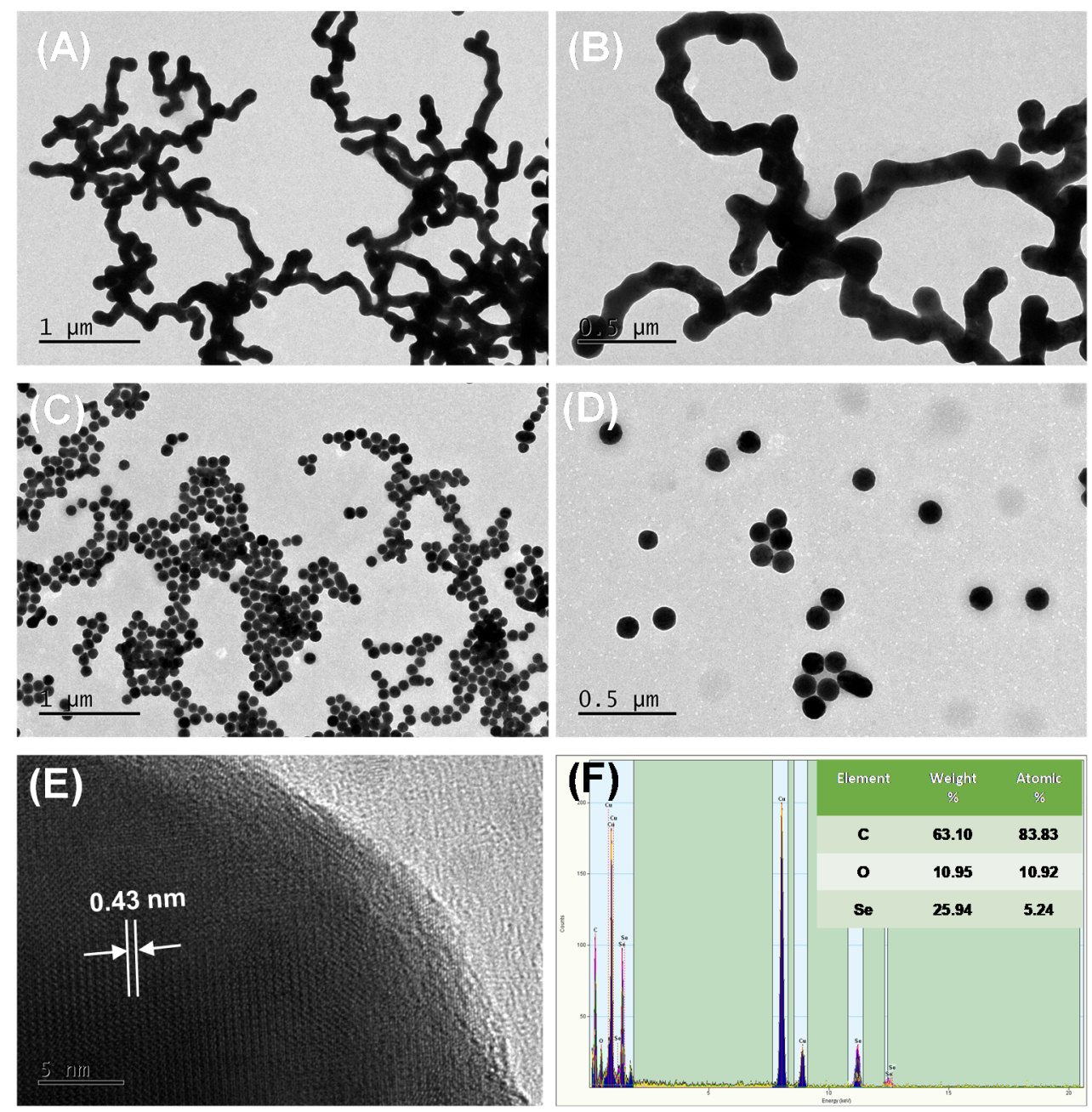

Figure 3. TEM images of SeNPs $(\mathbf{A}, \mathbf{B})$ and PSP-SeNPs in the presence of $0.1 \mathrm{mg} / \mathrm{mL}$ PSP (C,D). HRTEM of an individual PSP-SeNPs (E) and typical EDX from HRTEM (F).

\subsection{The Stability of SeNPs and PSP-SeNPs}

Stability is an important factor influencing the functionality and applications of nanomaterials. In this study, the effect of $\mathrm{pH}$, temperature, and ionic strength on the stability of PSP-SeNPs was investigated. As shown in Figure 4A, the average size of PSP-SeNPs significantly decreased from 1262 to $186 \mathrm{~nm}$ when $\mathrm{pH}$ was increased from 2 to 3 . It could be observed that no obvious changes occurred in the average size at $\mathrm{pH}$ range from 4 to 10. Similar results were also described previously on the stability of Polyporus umbellatus polysaccharide (PUP) coated SeNPs [34]. This might be ascribed to the protonation of PSP at $\mathrm{pH} 2$ that weakened the electrostatic interactions between SeNPs and PSP, leading to the aggregation of nanoparticles. Moreover, the $\zeta$-potential of PSP-SeNPs kept increasing with $\mathrm{pH}$ increased and reached the highest value of $-32.6 \mathrm{mV}$ at $\mathrm{pH}$ 7. A further increase in $\mathrm{pH}$ did not significantly affect the $\zeta$-potential of PSP. It has been reported that the $\zeta$-potential of nanoparticles was highly associated with the $\mathrm{pKa}$ value of the polysaccharides. The $\mathrm{pH}$ value higher than the $\mathrm{pKa}$ of polysaccharides resulted in more deprotonated characteristic groups, contributing to the increase in $\zeta$-potential [27]. The average size of PSP-SeNPs increased from 113 to $191 \mathrm{~nm}$, accompanied by the temperature increase from $25^{\circ} \mathrm{C}$ to $90{ }^{\circ} \mathrm{C}$ with a constant $\zeta$-potential at around $-31 \mathrm{mV}$ (Figure 4B). The result indicated that heating could increase the chances and strength of collisions, resulting in a larger size [29]. As shown in Figure 4C, the particle size of PSP-SeNPs exhibited a slight increase in 10 and $50 \mathrm{mM} \mathrm{NaCl}$ with decreased $\zeta$-potential, and steeply increased to $882 \mathrm{~nm}$ in a high concentration of $\mathrm{NaCl}$ at $100 \mathrm{mM}$. High ion strength could remarkably reduce the surface 
charge of nanoparticles due to the electrostatic interaction between positive charged $\mathrm{Na}^{+}$ and negatively charged PSP-SeNPs, resulting in the decrease of the electrostatic repulsion among nanoparticles [35]. It was observed that PSP-SeNPs were stable at about $113 \mathrm{~nm}$ for at least 20 days of storage (Figure 4D). The stability of PSP-SeNPs was higher than that of SeNPs decorated with a hyperbranched polysaccharide from Lignosus rhinocerotis 14 . It should be pointed out that SeNPs in the absence of PSP precipitated after 1-day storage (Figure 1). Moreover, the particle size of PSP-SeNPs only increased from 113 to $123 \mathrm{~nm}$ after 30 days of storage and the $\zeta$-potential of PSP-SeNPs presented at around $-30 \mathrm{mV}$ during the storage time, suggesting that PSP-SeNPs had better stability.
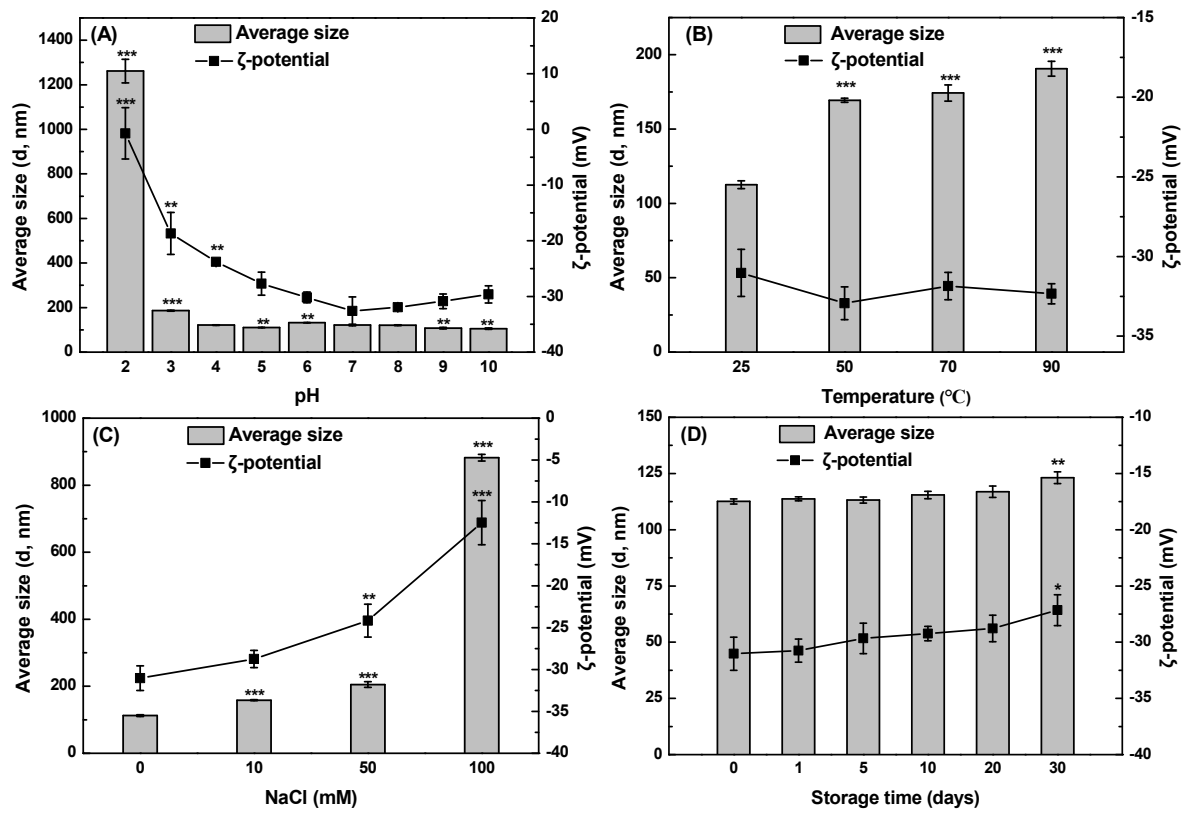

Figure 4. Effect of $\mathrm{pH}(\mathbf{A})$, temperature (B), ion strength $(\mathbf{C})$, and storage time (D) on the average size and $\zeta$-potential of PSP-SeNPs. Values marked with ${ }^{*}: p<0.05,{ }^{* *}: p<0.01$, and ${ }^{* * *}: p<0.001$ indicated significant differences when compared to the conditions of $\mathrm{pH}: 7$, temperature: $25^{\circ} \mathrm{C}, \mathrm{NaCl}: 0 \mathrm{mM}$, or storage time: 0 day.

\subsection{Characterization and Possible Stabilizing Mechanism of PSP-SeNPS}

The UV-vis spectra of PSP and PSP-SeNPs in the range of 190 to $800 \mathrm{~nm}$ were presented in Figure 5A. It was shown that no characteristic absorption peaks were observed on the UV-vis spectra of PSP at the concentration of $0.01 \mathrm{mg} / \mathrm{mL}$. The PSP-SeNPs exhibited wide absorption bands with a maximum absorption peak at about $288 \mathrm{~nm}$. The characteristic absorption peak corresponded to a localized surface plasmon response (LSPR), further demonstrating the formation of nanoparticles [36].

FTIR spectra were performed to clarify the interaction between PSP and SeNPs. In the spectrum of PSP (Figure 5B), the broad absorption band at nearly $3390 \mathrm{~cm}^{-1}$ was assigned to the $\mathrm{O}-\mathrm{H}$ stretching vibration. The peak presented at $2927 \mathrm{~cm}^{-1}$ was attributed to the C-H stretching vibration. The signals that occurred in the region of $1200-1000 \mathrm{~cm}^{-1}$ were associated with the $\mathrm{C}-\mathrm{O}$ stretching vibration, indicating the existence of a pyranose ring [37]. The FTIR spectrum of PSP-SeNPs was similar to that of the pure PSP, indicating the presence of PSP on the surface of SeNPs. In addition, the O-H stretching vibration occurred red-shift from $3390 \mathrm{~cm}^{-1}$ to $3376 \mathrm{~cm}^{-1}$, suggesting the formation of hydrogen bonds between SeNPs and the PSP chains [38]. Based on the above results, we proposed that the interaction mechanism was similar to the combination of arabinogalactans/and SeNPs as described previously [36]. Briefly, the $\mathrm{SeO}_{3}{ }^{2-}$ reacted with the $-\mathrm{OH}$ group in the PSP molecule to form special chain-shaped intermediates first, then reduced to the element Se by ascorbic acid. The Se atom further aggregated into the nucleus to form SeNPs as 
the reaction processed and the -OH groups of PSP were bound to the surface of SeNPs to prevent the aggregation of nanoparticles.
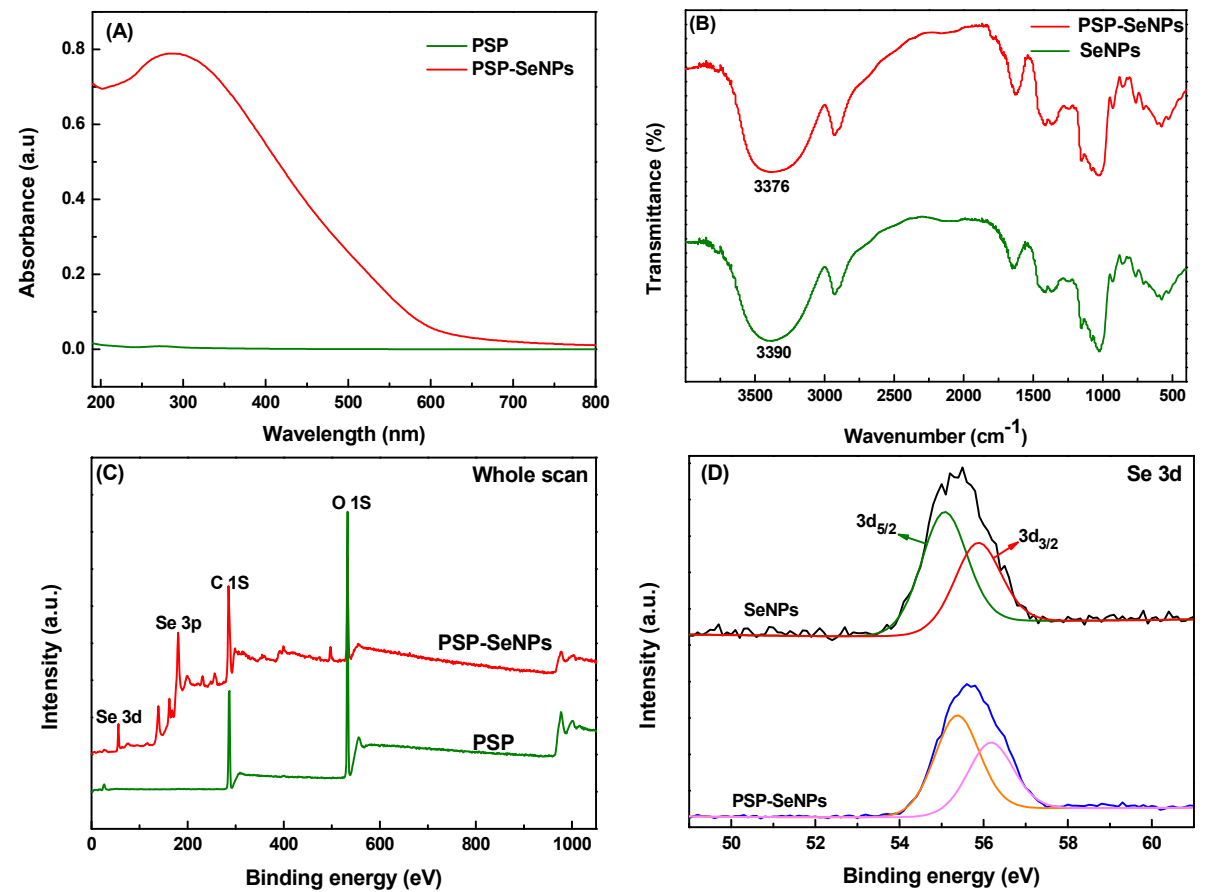

Figure 5. UV-vis spectra (A), FTIR spectra (B), XPS spectra (C), and XPS spectra of Se 3d (D) of PSP and PSP-SeNPs.

The XPS spectra were further used to analyze the valence state of selenium. The peaks of Se $3 d$ and 3p orbitals at the binding energy of 55.6 and $179.3 \mathrm{eV}$ (Figure 5C) indicated the zero-valent state of Se within the PSP-SeNPs [10]. As shown in Figure 5D, the peaks of Se $3 d_{5 / 2}$ and Se $3 d_{3 / 2}$ were up-shifted from 55.1 and 55.9 (SeNPs) to 55.4 and 56.2 (PSP-SeNPs), respectively. The results indicate that the Se $3 \mathrm{~d}$ orbit participated in the formation of PSPSeNPs [39], confirming that PSP was successfully conjugated to the SeNPs. Meanwhile, no peak was found at $59.5 \mathrm{eV}$, which represented the typical Se 3d signal of Se (IV), suggesting that Se (IV) was completely reduced to elemental selenium [40].

\subsection{Antioxidant Assays}

The DPPH and ABTS radical scavenging activity were measured in our study to evaluate the antioxidant activity of PSP, SeNPs, and PSP-SeNPs. As shown in Figure 6A, PSP exhibited a low DPPH radical scavenging ability at the tested concentrations. Both SeNPs and PSP-SeNPs had a concentration-dependent DPPH radical scavenging effect at $0.01-1.0 \mathrm{mg} / \mathrm{mL}$. PSP-SeNPs showed a higher scavenging ability than SeNPs. The scavenging effect of PSP-SeNPs reached $59 \%$ at the concentration of $1.0 \mathrm{mg} / \mathrm{mL}$, whereas SeNPs could only scavenge $43 \% \mathrm{DPPH}$ radical at the same concentration. This might be attributed to the enhanced hydrogen-donating ability of PSP-SeNPs to form a stable DPPH-H molecule [41]. Compared to the DPPH radical, all the tested samples performed more efficiently in scavenging ABTS radical (Figure 6B). Similar to the DPPH scavenging assay, the ABTS radical scavenging capacity of PSP-SeNPs was significantly stronger than that of PSP and SeNPs. At $1.0 \mathrm{mg} / \mathrm{mL}$, the scavenging effects of PSP, SeNPs, and PSP-SeNPs were $20 \%, 62 \%$ and $89 \%$, respectively. It has been reported that the DPPH scavenging ability of gum arabic-selenium nanocomposites was lower than $60 \%$ at $1.0 \mathrm{mg} / \mathrm{mL}$ [42]. The ABTS radical scavenging activity of SeNPs functionalized with a polysaccharide from Rosa roxburghii fruit only reached about $50 \%$ at $1.0 \mathrm{mg} / \mathrm{mL} 15$. The free radical scavenging ability of PSP-SeNPs synthesized in our study was higher than the above nanoparticles. Moreover, the results showed that the surface decoration of SeNPs with PSP 
could remarkably improve the antioxidant activity of SeNPs and PSP. PSP-SeNPs with a smaller size could provide more radical reactive sites due to their larger specific surface area, resulting in higher antioxidant activity $[29,43]$. However, barely SeNPs were easily aggregated with a decreased active surface to react with the free radicals, further reducing their biological activities [43].
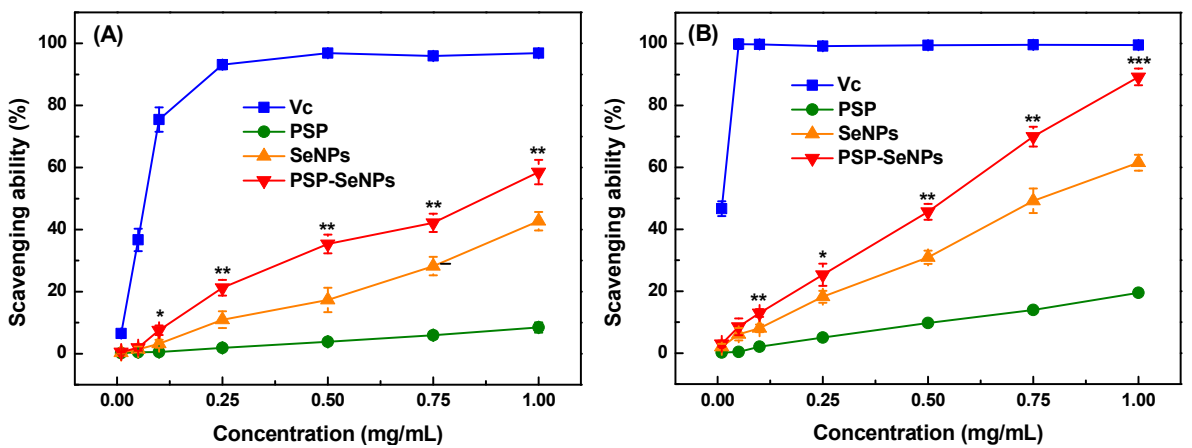

Figure 6. Antioxidant activities of PSP, SeNPs, and PSP-SeNPs in vitro. (A) DPPH radical scavenging activity. (B) ABTS radical scavenging activity. Ascorbic acid ( $\mathrm{Vc}_{\mathrm{c}}$ ) is used as a positive control. Values marked with $*: p<0.05,{ }^{* *}: p<0.01$, and ${ }^{* * *}: p<0.001$ indicated significant differences when compared to SeNPs at the same concentration.

\subsection{Effects of PSP-SeNPs on $\mathrm{H}_{2} \mathrm{O}_{2}$-Induced PC-12 Cells Toxicity}

Although the free radical scavenging assays proved the excellent antioxidant activity of PSP-SeNPs, the antioxidant assays based on chemical reactions may not necessarily reflect the behavior of antioxidants in biological systems [16]. Thus, the effect of different selenium species on oxidative stress-induced damage to PC-12 cells was further investigated by MTT assay. As depicted in Figure 7A, the cell viability was higher than $90 \%$ when incubated with SeNPs and PSP-SeNPs at the concentration of 1-20 $\mu \mathrm{g} / \mathrm{mL}$. However, the cell viability dramatically decreased to $67 \%$ after treatment with $20 \mu \mathrm{g} / \mathrm{mL} \mathrm{Na} \mathrm{SeO}_{3}$, suggesting that both SeNPs and PSP-SeNPs showed lower cytotoxicity than $\mathrm{Na}_{2} \mathrm{SeO}_{3}$.
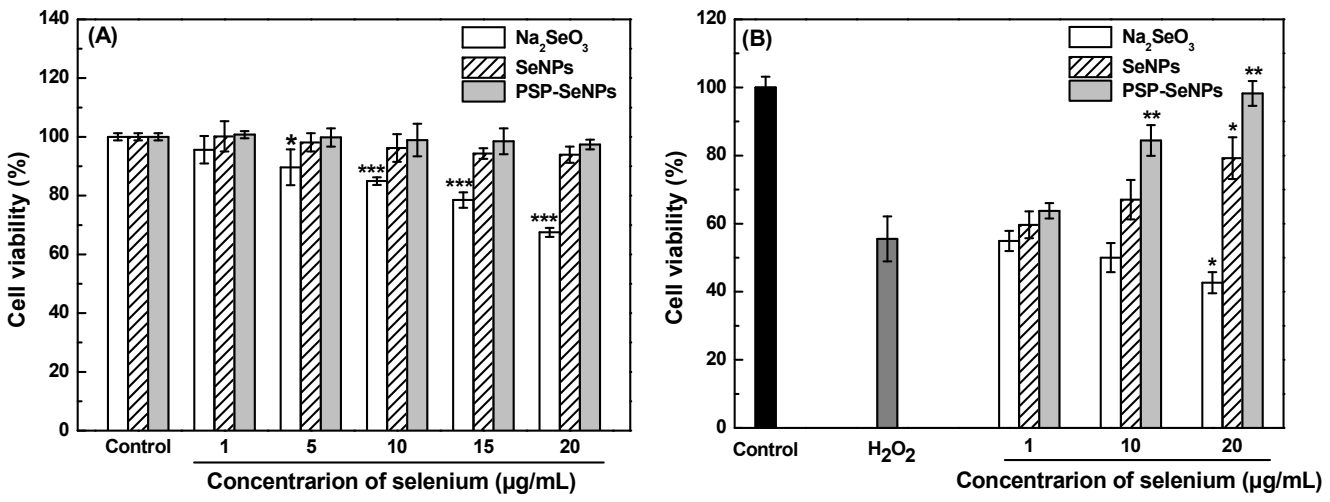

Figure 7. Effects of sodium selenite $\left(\mathrm{Na}_{2} \mathrm{SeO}_{3}\right)$, SeNPs, and PSP-SeNPs on the viability of PC-12 cells (A). Values marked with $* p<0.05$ and ${ }^{* * *}: p<0.001$ indicated significant differences when compared to the control group. The protective effect against $\mathrm{H}_{2} \mathrm{O}_{2}(0.5 \mu \mathrm{M})$-induced PC-12 cells toxicity by MTT assay (B). Values marked with $*$ : $p<0.05$ and ${ }^{* *}: p<0.01$ indicated significant differences when compared to the $\mathrm{H}_{2} \mathrm{O}_{2}$ treated group.

The overproduction of reactive oxygen species (ROS) is considered to be the main cause of oxidative damage [44]. Herein, exogenous $\mathrm{H}_{2} \mathrm{O}_{2}$ was used as an inducer of cell damage in our model. PC-12 cells incubated with $500 \mu \mathrm{M} \mathrm{H}_{2} \mathrm{O}_{2}$ showed a remarkable decrease of cell viability reaching $56 \%$ (Figure 7B). However, the viability of PC-12 cells decreased to $55 \%, 50 \%$, and $43 \%$ when pretreated with $\mathrm{Na}_{2} \mathrm{SeO}_{3}$ at concentrations of 1 , 
10 , and $20 \mu \mathrm{g} / \mathrm{mL}$, respectively. Interestingly, compared with the $\mathrm{H}_{2} \mathrm{O}_{2}$-induced oxidative stress model group, cells pretreated with SeNPs or PSP-SeNPs alleviated the $\mathrm{H}_{2} \mathrm{O}_{2}$-induced toxicity on PC-12 cells in a concentration-dependent manner, as reflected by the increase in cell viability. The viability of PC-12 cells pretreated with $20 \mu \mathrm{g} / \mathrm{mL}$ SeNPs or PSP-SeNPs significantly increased to $79 \%$ and $98 \%$, respectively. In addition, the protective effect of PSP-SeNPs on $\mathrm{H}_{2} \mathrm{O}_{2}$-induced oxidative damage on PC-12 cells was better than that of SeNPs. The results confirmed that PSP-SeNPs had excellent antioxidant activity in cells, which may be associated with the free radical scavenging ability.

\title{
4. Conclusions
}

Our present study provided a facile approach for the synthesis of size-controlled SeNPs by using PSP as a stabilizer in the redox system of sodium selenite and ascorbic acid. The synthesized PSP-SeNPs presented a monodisperse spherical structure with zero-valent Se. The interaction between the hydroxyl groups of PSP chains and the surface of SeNPs contributed to the stable structure of PSP-SeNPs. Furthermore, PSP-SeNPs exhibited stronger free radical scavenging ability and a higher protective effect against $\mathrm{H}_{2} \mathrm{O}_{2}$-induced PC-12 cell death than SeNPs. Our findings not only provide the foundations for the utilization of PSP in the development of stable SeNPs but also emphasize the potential application of PSP-SeNPs as an antioxidant in food additives, dietary supplements, and nutraceuticals.

\begin{abstract}
Author Contributions: Conceptualization, W.C. and H.C.; methodology, W.C.; software, W.C.; validation, W.C.; formal analysis, W.C. and H.C.; investigation, W.C.; resources, W.X.; data curation, H.C.; writing-original draft preparation, W.C.; writing—review and editing, H.C.; visualization, W.X.; supervision, W.X.; project administration, W.C. and H.C.; funding acquisition, W.C. and H.C. All authors have read and agreed to the published version of the manuscript.
\end{abstract}

Funding: This research was funded by the China Postdoctoral Science Foundation (Grant No. 2021M691288) and the National Natural Science Foundation of China (Grant No. 32101939).

Institutional Review Board Statement: Not applicable.

Informed Consent Statement: Not applicable.

Data Availability Statement: The data presented in this study are available in this manuscript.

Conflicts of Interest: The authors declare no conflict of interest.

\section{References}

1. Hariharan, S.; Dharmaraj, S. Selenium and selenoproteins: It's role in regulation of inflammation. Inflammopharmacology 2020, 28, 667-695. [CrossRef] [PubMed]

2. Kursvietiene, L.; Mongirdiene, A.; Bernatoniene, J.; Sulinskiene, J.; Staneviciene, I. Selenium anticancer properties and impact on cellular redox status. Antioxidants 2020, 9, 80. [CrossRef] [PubMed]

3. Dawood, M.A.O.; El Basuini, M.F.; Yilmaz, S.; Abdel-Latif, H.M.R.; Kari, Z.A.; Razab, M.; Ahmed, H.A.; Alagawany, M.; Gewaily, M.S. Selenium nanoparticles as a natural antioxidant and metabolic regulator in aquaculture: A review. Antioxidants 2021, 10, 1364. [CrossRef] [PubMed]

4. Zhu, X.K.; Jiang, M.D.; Song, E.Q.; Jiang, X.J.; Song, Y. Selenium deficiency sensitizes the skin for UVB-induced oxidative damage and inflammation which involved the activation of p38 MAPK signaling. Food Chem. Toxicol. 2015, 75, 139-145. [CrossRef] [PubMed]

5. Zhang, L.Q.; Song, H.X.; Guo, Y.B.; Fan, B.; Huang, Y.T.; Mao, X.F.; Liang, K.H.; Hu, Z.Q.; Sun, X.D.; Fang, Y.; et al. Benefit-risk assessment of dietary selenium and its associated metals intake in China (2017-2019): Is current selenium-rich agro-food safe enough? J. Hazard. Mater. 2020, 398, 123224. [CrossRef] [PubMed]

6. Jin, Y.X.; Cai, L.Q.; Yang, Q.; Luo, Z.Y.; Liang, L.; Liang, Y.X.; Wu, B.L.; Ding, L.; Zhang, D.D.; Xu, X.J.; et al. Anti-leukemia activities of selenium nanoparticles embedded in nanotube consisted of triple-helix beta-D-glucan. Carbohydr. Polym. 2020, 240, 116329. [CrossRef] [PubMed]

7. Huang, Y.Y.; Su, E.Z.; Ren, J.S.; Qu, X.G. The recent biological applications of selenium-based nanomaterials. Nano Today 2021, 38, 101205. [CrossRef]

8. Ye, X.G.; Chen, Z.Z.; Zhang, Y.Y.; Mu, J.J.; Chen, L.Y.; Li, B.; Lin, X.R. Construction, characterization, and bioactive evaluation of nano-selenium stabilized by green tea nano-aggregates. LWT-Food Sci. Technol. 2020, 129, 109475. [CrossRef]

9. Yan, J.K.; Qiu, W.Y.; Wang, Y.Y.; Wang, W.H.; Yang, Y.; Zhang, H.N. Fabrication and stabilization of biocompatible selenium nanoparticles by carboxylic curdlans with various molecular properties. Carbohydr. Polym. 2018, 179, 19-27. [CrossRef] 
10. Liu, L.; Xiao, Z.; Niu, S.; He, Y.; Wang, G.; Pei, X.; Tao, W.; Wang, M. Preparation, characteristics and feeble induced-apoptosis performance of non-dialysis requiring selenium nanoparticles@chitosan. Mater. Des. 2019, 182, 108024. [CrossRef]

11. Ayadi, F.; Bayer, I.S.; Marras, S.; Athanassiou, A. Synthesis of water dispersed nanoparticles from different polysaccharides and their application in drug release. Carbohydr. Polym. 2016, 136, 282-291. [CrossRef] [PubMed]

12. Shi, X.D.; Tian, Y.Q.; Wu, J.L.; Wang, S.Y. Synthesis, characterization, and biological activity of selenium nanoparticles conjugated with polysaccharides. Crit. Rev. Food Sci. Nutr. 2021, 61, 2225-2236. [CrossRef] [PubMed]

13. Chen, W.W.; Li, Y.F.; Yang, S.; Yue, L.; Jiang, Q.; Xia, W.S. Synthesis and antioxidant properties of chitosan and carboxymethyl chitosan-stabilized selenium nanoparticles. Carbohydr. Polym. 2015, 132, 574-581. [CrossRef]

14. Cai, W.F.; Hu, T.; Bakry, A.M.; Zheng, Z.M.; Xiao, Y.D.; Huang, Q.L. Effect of ultrasound on size, morphology, stability and antioxidant activity of selenium nanoparticles dispersed by a hyperbranched polysaccharide from Lignosus rhinocerotis. Ultrason. Sonochem. 2018, 42, 823-831. [CrossRef] [PubMed]

15. Lei, W.; Chao, L.; Qiang, H.; Xiong, F. Biofunctionalization of selenium nanoparticles with a polysaccharide from Rosa roxburghii fruit and their protective effect against $\mathrm{H}_{2} \mathrm{O}_{2}$-induced apoptosis in INS-1 cells. Food Funct. 2019, 10, 539-553. [CrossRef]

16. Zhang, W.; Zhang, J.; Ding, D.; Zhang, L.; Muehlmann, L.A.; Deng, S.-E.; Wang, X.; Li, W.; Zhang, W. Synthesis and antioxidant properties of Lycium barbarum polysaccharides capped selenium nanoparticles using tea extract. Artif. Cells Nanomed. Biotechnol. 2018, 46, 1463-1470. [CrossRef]

17. Xie, J.H.; Jin, M.L.; Morris, G.A.; Zha, X.Q.; Chen, H.Q.; Yi, Y.; Li, J.E.; Wang, Z.J.; Gao, J.; Nie, S.P.; et al. Advances on bioactive polysaccharides from medicinal plants. Crit. Rev. Food Sci. Nutr. 2016, 56, S60-S84. [CrossRef]

18. Li, X.J.; Chen, Q.; Liu, G.K.; Xu, H.R.; Zhang, X. Chemical elucidation of an arabinogalactan from rhizome of Polygonatum sibiricum with antioxidant activities. Int. J. Biol. Macromol. 2021, 190, 730-738. [CrossRef]

19. Huang, S.; Yuan, H.Y.; Li, W.Q.; Liu, X.Y.; Zhang, X.J.; Xiang, D.X.; Luo, S.L. Polygonatum sibiricum polysaccharides protect against MPP-induced neurotoxicity via the Akt/mTOR and Nrf2 pathways. Oxid. Med. Cell. Longev. 2021, 2021, 8843899. [CrossRef]

20. Wang, J.; Lu, C.-S.; Liu, D.-Y.; Xu, Y.-T.; Zhu, Y.; Wu, H.-H. Constituents from Polygonatum sibiricum and their inhibitions on the formation of advanced glycosylation end products. J. Asian Nat. Prod. Res. 2016, 18, 697-704. [CrossRef]

21. Cui, X.; Wang, S.; Cao, H.; Guo, H.; Li, Y.; Xu, F.; Zheng, M.; Xi, X.; Han, C. A Review: The bioactivities and pharmacological applications of Polygonatum sibiricum polysaccharides. Molecules 2018, 23, 1170. [CrossRef] [PubMed]

22. Liu, J.; Li, T.Y.; Chen, H.Y.; Yu, Q.; Yan, C.Y. Structural characterization and osteogenic activity in vitro of novel polysaccharides from the rhizome of Polygonatum sibiricum. Food Funct. 2021, 12, 6626-6636. [CrossRef]

23. Chen, Z.; Liu, J.; Kong, X.; Li, H. Characterization and immunological activities of polysaccharides from Polygonatum sibiricum. Biol. Pharm. Bull. 2020, 43, 959-967. [CrossRef] [PubMed]

24. Sun, T.T.; Zhang, H.; Li, Y.; Liu, Y.; Dai, W.; Fang, J.; Cao, C.; Die, Y.; Liu, Q.; Wang, C.L.; et al. Physicochemical properties and immunological activities of polysaccharides from both crude and wine-processed Polygonatum sibiricum. Int. J. Biol. Macromol. 2020, 143, 255-264. [CrossRef]

25. Ma, W.; Wei, S.; Peng, W.; Sun, T.; Huang, J.; Yu, R.; Zhang, B.; Li, W. Antioxidant effect of Polygonatum sibiricum polysaccharides in D-galactose-induced heart aging mice. Biomed. Res. Int. 2021, 2021, 6688855. [CrossRef] [PubMed]

26. Wang, G.J.; Fu, Y.W.; Li, J.J.; Li, Y.N.; Zhao, Q.H.; Hu, A.L.; Xu, C.D.; Shao, D.L.; Chen, W.J. Aqueous extract of Polygonatum sibiricum ameliorates ethanol-induced mice liver injury via regulation of the Nrf2/ARE pathway. J. Food Biochem. 2021, 45, 11. [CrossRef] [PubMed]

27. Song, X.; Chen, Y.; Sun, H.; Liu, X.; Leng, X. Physicochemical stability and functional properties of selenium nanoparticles stabilized by chitosan, carrageenan, and gum Arabic. Carbohydr. Polym. 2021, 255, 117379. [CrossRef]

28. Wang, T.; Zhao, H.; Bi, Y.; Fan, X. Preparation and antioxidant activity of selenium nanoparticles decorated by polysaccharides from Sargassum fusiforme. J. Food Sci. 2021, 86, 977-986. [CrossRef]

29. Chen, W.W.; Yue, L.; Jiang, Q.X.; Liu, X.L.; Xia, W.S. Synthesis of varisized chitosan-selenium nanocomposites through heating treatment and evaluation of their antioxidant properties. Int. J. Biol. Macromol. 2018, 114, 751-758. [CrossRef]

30. Li, H.Y.; Liu, D.D.; Li, S.H.; Xue, C.H. Synthesis and cytotoxicity of selenium nanoparticles stabilized by alpha-D-glucan from Castanea mollissima Blume. Int. J. Biol. Macromol. 2019, 129, 818-826. [CrossRef]

31. Ren, L.R.; Wu, Z.C.; Ma, Y.; Jian, W.J.; Xiong, H.J.; Zhou, L.N. Preparation and growth-promoting effect of selenium nanoparticles capped by polysaccharide-protein complexes on tilapia. J. Sci. Food Agric. 2021, 101, 476-485. [CrossRef] [PubMed]

32. Chen, W.W.; Yue, L.; Jiang, Q.X.; Xia, W.S. Effect of chitosan with different molecular weight on the stability, antioxidant and anticancer activities of well-dispersed selenium nanoparticles. IET Nanobiotechnol. 2019, 13, 30-35. [CrossRef]

33. Xiao, Y.D.; Huang, Q.L.; Zheng, Z.M.; Guan, H.; Liu, S.Y. Construction of a Cordyceps sinensis exopolysaccharide-conjugated selenium nanoparticles and enhancement of their antioxidant activities. Int. J. Biol. Macromol. 2017, 99, 483-491. [CrossRef] [PubMed]

34. Gao, X.; Li, X.; Mu, J.; Ho, C.-T.; Su, J.; Zhang, Y.; Lin, X.; Chen, Z.; Li, B.; Xie, Y. Preparation, physicochemical characterization, and anti-proliferation of selenium nanoparticles stabilized by Polyporus umbellatus polysaccharide. Int. J. Biol. Macromol. 2020, 152, 605-615. [CrossRef] [PubMed]

35. Evageliou, V.I.; Ryan, P.M.; Morris, E.R. Effect of monovalent cations on calcium-induced assemblies of kappa carrageenan. Food Hydrocoll. 2019, 86, 141-145. [CrossRef] 
36. Tang, S.; Wang, T.; Jiang, M.; Huang, C.; Lai, C.; Fan, Y.; Yong, Q. Construction of arabinogalactans/selenium nanoparticles composites for enhancement of the antitumor activity. Int. J. Biol. Macromol. 2019, 128, 444-451. [CrossRef]

37. Wang, Y.; Liu, N.; Xue, X.; Li, Q.; Sun, D.; Zhao, Z. Purification, structural characterization and in vivo immunoregulatory activity of a novel polysaccharide from Polygonatum sibiricum. Int. J. Biol. Macromol. 2020, 160, 688-694. [CrossRef]

38. Zhou, L.; Song, Z.; Zhang, S.; Li, Y.; Xu, J.; Guo, Y. Construction and antitumor activity of selenium nanoparticles decorated with the polysaccharide extracted from Citrus limon (L.) Burm. f. (Rutaceae). Int. J. Biol. Macromol. 2021, 188, 904-913. [CrossRef]

39. Liu, W.; Li, X.; Wong, Y.-S.; Zheng, W.; Zhang, Y.; Cao, W.; Chen, T. Selenium nanoparticles as a carrier of 5-fluorouracil to achieve anticancer synergism. ACS Nano 2012, 6, 6578-6591. [CrossRef]

40. Chunyue, Z.; Xiaona, Z.; Guanghua, Z.; Fazheng, R.; Xiaojing, L. Synthesis, characterization, and controlled release of selenium nanoparticles stabilized by chitosan of different molecular weights. Carbohydr. Polym. 2015, 134, 158-166. [CrossRef]

41. Cheng, Y.; Xiao, X.; Li, X.; Song, D.; Lu, Z.; Wang, F.; Wang, Y. Characterization, antioxidant property and cytoprotection of exopolysaccharide-capped elemental selenium particles synthesized by Bacillus paralicheniformis SR14. Carbohydr. Polym. 2017, 178, 18-26. [CrossRef] [PubMed]

42. Kong, H.; Yang, J.; Zhang, Y.; Fang, Y.; Nishinari, K.; Phillips, G.O. Synthesis and antioxidant properties of gum arabic-stabilized selenium nanoparticles. Int. J. Biol. Macromol. 2014, 65, 155-162. [CrossRef] [PubMed]

43. Tang, L.; Luo, X.; Wang, M.; Wang, Z.; Guo, J.; Kong, F.; Bi, Y. Synthesis, characterization, in vitro antioxidant and hypoglycemic activities of selenium nanoparticles decorated with polysaccharides of Gracilaria lemaneiformis. Int. J. Biol. Macromol. 2021, 193, 923-932. [CrossRef] [PubMed]

44. Qi, Y.; Yi, P.; He, T.; Song, X.; Liu, Y.; Li, Q.; Zheng, J.; Song, R.; Liu, C.; Zhang, Z.; et al. Quercetin-loaded selenium nanoparticles inhibit amyloid-beta aggregation and exhibit antioxidant activity. Colloid Surf. A-Physicochem. Eng. Asp. 2020, $602,125058$. [CrossRef] 